\title{
ESTADO, PLURINACIONALIDAD Y PUEBLOS INDÍGENAS EN EL ECUADOR CONTEMPORÁNEO
}

\author{
Jorge Resina de Fuente \\ jresina@cps.ucm.es / jorge.resina@gmail.com \\ Investigador Facultad Ciencias Políticas y Sociología, \\ Universidad Complutense de Madrid
}

\section{RESUMEN}

Tres décadas después del inicio de la transición a la democracia, el Ecuador se encuentra ahora ante el reto de dar contenido al Estado Plurinacional, aprobado en la Constitución de Montecristi en 2008. A pesar de esta reciente constitucionalización, la plurinacionalidad es una demanda histórica planteada por la Confederación de Nacionalidades Indígenas del Ecuador (CONAIE) desde finales de los años ochenta. Rasgo que la convierte en un concepto complejo y en disputa que coloca al país en una encrucijada, con varios modelos políticos en pugna. A partir de aquí, este artículo pretende analizar la relación establecida entre el Estado y los pueblos y las nacionalidades indígenas en las últimas décadas, y reflexionar sobre los vínculos entre la democracia y lo plurinacional.

Palabras clave: Estado Plurinacional, ciudadanía étnica, pueblos y nacionalidades indígenas y democratización.

\section{ABSTRACT}

After three decades from the start of the transition to democracy, Ecuador faces now the challenge of giving content to the Plurinational State, approved in the Constitution of Montecristi in 2008. Despite this recent constitutionalization, plurinationality is a historic demand raised by the Confederation of Indigenous Nationalities of Ecuador (CONAIE) since the late eighties. Feature that makes it a complex and contested concept that puts the country in a time of crossroads, with several political models in 
competition. From here, this article analyzes the relationship established between the state and indigenous peoples and nationalities in recent decades and reflects on the linkages between democracy and plurinacionality.

Key Words: Plurinational State, ethnic citizenship, indigenous peoples and nationalities, democratization

\section{INTRODUCCIÓN}

¿Qué piden los indígenas? $\mathrm{O}$, como algunos se preguntan, ¿qué más piden los indígenas? Parece que tras más de dos décadas de movilizaciones, reconocimientos y logros jurídicos y constitucionales en algunos países de América Latina, las demandas de los pueblos y las nacionalidades indígenas han quedado ya satisfechas, y a partir de ahí tan solo se trataría de concretar o de matizar algunas de sus reivindicaciones. Sin embargo, las cosas parecen ir por otro lado. Uno de los casos más paradigmáticos es el ecuatoriano, país donde el nivel de conflicto entre los indígenas y el gobierno asciende a cotas que se creían superadas. Circunstancia que, a priori, puede sorprender si se tiene, sobre todo, en cuenta la constitucionalización de la plurinacionalidad en 2008 y el hecho de que sea un gobierno que se autodefine como progresista, bajo la estela del Socialismo del siglo XXI, el que esté en el poder.

Sin duda, el juego político interno, los equilibrios de fuerzas, las inercias de la cultura política, las dinámicas de las distintas organizaciones y las agregaciones de intereses tienen un papel destacado y son, probablemente, parte de la explicación de esta contienda. Si bien, aquí se pretende plantear dicho conflicto como un choque de concepciones alrededor de la plurinacionalidad. Una fricción de naturaleza estructural que tiene sus raíces en la propia construcción de la democracia en el país y en la manera en que el Estado, por un lado, se inserta en la economía internacional y, por el otro, ha intentado resolver la cuestión de la diversidad étnica a partir de una arquitectura monocultural. 
Cabe preguntarse, además, si lo plurinacional, como tal, se trata de un punto de llegada o si, por el contrario, supone un punto de partida para la construcción de un nuevo modelo de organización política de la sociedad. En ese sentido, puede afirmarse que la Revolución Ciudadana impulsada por el presidente Rafael Correa da por buena la primera respuesta, ${ }^{1}$ mientras que la Confederación de Nacionalidades Indígenas del Ecuador (CONAIE), principal organización indígena del país, hace lo propio con la segunda. En todo caso, hay que apuntar que la plurinacionalidad no puede considerarse una demanda nueva en el contexto ecuatoriano sino, más bien, debe interpretarse como una reivindicación histórica de la CONAIE, que en 1988 ya planteó al gobierno de Rodrigo Borja un anteproyecto de ley en el que aquélla se formulaba de manera explícita como aspiración política (Yashar, 2005: 132).

El objetivo de este artículo es inquirir sobre el carácter conflictivo de la plurinacionalidad. Para lo cual se propone, en primer lugar, trazar una periodización de la transición a la democracia «desde arriba» en el contexto latinoamericano desde los años ochenta y analizar las transformaciones derivadas en la matriz del Estado. Junto a ello, y como claroscuro, se plantea el estudio de estos procesos «desde abajo», a partir de la réplica dada por las prácticas de luchas populares encabezadas por los pueblos y las nacionalidades indígenas.

Este planteamiento, en línea con lo que argumenta Segato (2007: 37), pretende recoger dos tendencias opuestas y simultáneas de la globalización: por un lado, un proceso de homogeneización y, por el otro, uno de heterogeneidad, «donde pueblos históricamente oprimidos por los Estados-nacionales inscriben sus identidades tornándolas visibles en el orden mundial» (Varese, en Segato, 2007: 37), con el objetivo de lograr una explicación más completa.

Se genera, de esta forma, una dialéctica que fuerza al Estado a dar una respuesta a las presiones «desde abajo» y que termina con el reconocimiento estatal de los derechos indígenas. Ello nos lleva a la segunda parte, en la que se analiza la forma de relación 
que el Estado ha establecido con los indígenas a través de la ciudadanía étnica, como mediación inscrita dentro de un modelo de organización multicultural de la sociedad.

Y en tercer y último lugar se presenta el debate sobre lo plurinacional en el Ecuador y la actual coyuntura de encrucijada, donde algunos planteamientos cuestionan los límites de la democracia construida durante los últimos treinta años, y en donde queda aún por definir si se dará continuidad a las formas de organización multicultural o, por el contrario, se abrirá una profunda transformación del sistema político, económico, social y cultural. Para esta última parte se incluye trabajo de campo, mediante la utilización de algunos fragmentos de entrevistas semi-estructuradas realizadas a dirigentes políticos indígenas, ${ }^{2}$ con el fin de interrogarse sobre los límites y las posibilidades de la construcción de un Estado Plurinacional desde la propuesta indígena.

La hipótesis inicial afirma: 1) que la ciudadanía étnica es una respuesta histórica planteada por el Estado poscorporativista ante la presión de las demandas indígenas en un contexto de políticas neoliberales en América Latina; 2) que dicho modelo ha supuesto, por un lado, un mecanismo de reconocimiento formal de los derechos indígenas, pero que, por el otro, ha imposibilitado la práctica material de los mismos, y 3) que la propuesta plurinacional formulada por los pueblos y las nacionalidades indígenas puede suponer un cuestionamiento a ese modelo de organización social, al plantear una reflexión sobre el poder y un nuevo equilibrio en el juego de la democracia.

Esta hipótesis se asienta en otros tantos presupuestos. Primero, en el cambio de régimen de ciudadanía que acompaña la transformación del Estado, que tiene como consecuencia la desaparición de los vínculos corporativistas y la creación de un nuevo sistema de relaciones entre el Estado y los pueblos indígenas, en el que entran en escena nuevos actores (como empresas multinacionales), lo local toma relevancia y se exaltan los derechos individuales (Yashar, 2005). Segundo, en la construcción del «indio permitido» (Hale, 2002), por el que los Estados a través del multiculturalismo convierten en demandas culturales todas las reivindicaciones indígenas, anulando los procesos de cambio socioeconómico. Tercero, en que el modelo de democracia 
consolidado en la región se reconoce como tal por la legitimidad electoral con la que dota al sistema político, pero no por ser el principio organizador del mismo, cuyo sustituto es el mercado (Lechner, 1997).

\section{TRES DÉCADAS DE TRANSICIÓN HACIA LA DEMOCRACIA}

\section{EL PUNTO DE RUPTURA CON LAS DICTADURAS (DÉCADA DE LOS OCHENTA)}

De forma bastante dramática, casi todos los países latinoamericanos tuvieron durante la segunda mitad del siglo XX episodios dictatoriales. No fue hasta la década de los ochenta - y no sin excepciones - cuando comenzó la ola democratizadora que condujo a sistemas formalmente democráticos. Como señala Cavarozzi (1991), estos procesos toman distintas rutas, según el país, y cada tipo de transición lleva a diferentes subespecies de democracia. Además, se trata de movimientos que pueden ser reversibles (como así se demostró en el Perú de Alberto Fujimori durante los años noventa), tanto en lo referido al modelo alcanzado como a los avances específicos que puedan lograrse dentro de él.

De manera general, Garretón (1997) apunta tres grandes modalidades de transición que han caracterizado a América Latina: la fundacional, entendida como aquella que proviene de una revolución o de una guerra civil (el ejemplo de Cuba o de los países centroamericanos); la propiamente transicional, donde el régimen militar institucionalizado se quiebra (como ocurrió en los países del Cono Sur y en los Andinos. A este respecto, el caso del Ecuador con Rodríguez Lara es muestra de ello); y la extensiva, donde un régimen semiautoritario liberaliza algunas de sus estructuras políticas (como México o Colombia).

Estos procesos de transición «desde arriba» suceden durante el periodo que en América Latina se denominó «la década perdida», producto de la crisis de la deuda y de la descomposición del modelo económico desarrollista, una circunstancia que no puede obviarse y que forja de manera importante la génesis de las democracias establecidas 
desde entonces, que nacen acompañadas de importantes paquetes de reformas neoliberales.

La democratización, por tanto, coincide con la crisis de la balanza de pagos y tiene que iniciarse en un contexto de apertura económica y comercial hacia el exterior, y de ajuste fiscal y «estabilización» hacia el interior, de recomposición del capitalismo y de un nuevo modo de inserción en la economía internacional. En términos de Estado, este cruce de procesos supone el fin de la matriz estado-céntrica y del modelo estatal establecido en la región desde los años treinta, caracterizado entre otros rasgos por lo nacional-popular en lo ideológico, el desarrollismo y la industrialización en lo económico, el corporativismo clasista en lo social, y el indigenismo en lo étnicocultural. De esta forma, queda desarticulada la matriz previa, pero sin lograr articular una nueva matriz estatal. Un problema que arrastran buena parte de los países latinoamericanos, prácticamente, hasta nuestros días.

La quiebra de este modelo de Estado tiene consecuencias «abajo». El Estado corporativo se había caracterizado, al menos en los países centroandinos, por considerar a los indígenas, en términos de clase, como parte del campesinado. El indigenismo impulsado desde arriba buscaba la integración indígena, pero lo hacía a partir de un proyecto culturalmente homogeneizante. La disolución de esta forma de relación rompía los lazos preexistentes y favorecía unas condiciones proclives a generar una toma de conciencia de lo étnico entre los indígenas, por encima de las relaciones clasistas que habían dominado en las décadas anteriores. Como afirma Dávalos, la categoría de campesino se había convertido «en una mordaza epistemológica» para comprender su propia condición de indígenas (2005: 342).

Esta ruptura, junto a las reformas agrarias de décadas anteriores, el fin de la guerra fría y el inicio de la globalización neoliberal, los movimientos migratorios hacia las ciudades, el declive de la influencia de la Iglesia católica y la creciente presencia de la cooperación internacional, dio paso a un nuevo periodo, categorizado por Bengoa como etnogénesis (2000). 
En el Ecuador, la transición a la democracia no fue especialmente violenta. A diferencia de otros casos regionales, el proceso se caracterizó por ser prácticamente incruento. Si bien este rasgo pasará a ser huella genética de la democracia ecuatoriana, ya que se caracteriza como una transición dirigida por los militares, lo que influirá en la posterior inmadurez democrática del sistema político del país (Zamosc, 2007).

Por otra parte, los procesos de reforma agraria impulsados en 1964 y 1973 por el Estado central son abandonados y sustituidos por una nueva política asociada al desarrollo rural, donde ONGs e instancias internacionales, como el Banco Mundial, comienzan a adquirir importancia como gestores del territorio y de la identidad, bajo la fórmula del «etnodesarrollo» (Bretón, 2007: 97).

No es de extrañar, por tanto, que sea durante la década de los ochenta (1986) cuando se funde la CONAIE, al integrar en una sola confederación estatal a las dos principales organizaciones indígenas del país, la representante de la sierra ECUARUNARI (creada en 1973), y la amazónica CONFENIAE (1980). Y al sintetizar, de este modo, demandas y propuestas bastantes diferentes, si se tienen en cuenta los rasgos de la Amazonía (práctica ausencia del Estado, amenaza extractiva por parte de las multinacionales petroleras y procesos de colonización) con respecto a los de la sierra (con una marcada tradición organizativa y con luchas campesinas centradas en la tierra). No es hasta 1999, cuando se integra la tercera federación, la CONAICE, representante de la costa.

LA DEMOCRACIA DELEGATIVA Y LAS PRIMERAS GRANDES MOVILIZACIONES (DÉCADA DE LOS NOVENTA)

La transición a la democracia había cumplido uno de sus principales objetivos al superar el periodo de dictaduras militares. Si bien no ha sido capaz de satisfacer buena parte de las expectativas ciudadanas generadas, como demuestra la inestabilidad posterior en la región o los varios intentos de refundar las democracias y de crear nuevos regímenes. La profunda crisis económica, la permanencia de rasgos autoritarios en el sistema político, la inercia clientelística y la debilidad institucional de estos primeros años han 
conducido a un subgénero de democracia denominada por O'Donnell (1994) democracia delegativa, característica en la mayoría de los países de América Latina, y en la que ni siquiera se ha logrado consolidar rasgos propios de la democracia liberal, como la representación o el equilibrio de poderes. La ausencia de instituciones fuertes, que cuenten con la afección social y la capacidad política necesarias, se ha visto sustituida por un poder reforzado en la figura presidencial, de forma que los mecanismos de accountability dejan paso a la capacidad de interpretación del presidente.

Estas fallas que, a pesar de las reformas posteriores, no desaparecen del todo, intentan subsanarse con un hiperpresidencialismo, donde la omnipotencia de los presidentes (en sistemas que son presidenciales) termina en impotencia política, al derivar en incapacidad de transformación, lo cual convierte en irrelevante la democracia -en el sentido dado por O’Donnell- como régimen capaz de resolver los conflictos a través - y no fuera- de ella. Esto puede explicar parte del elevado nivel de informalidad y de conflictividad política que ha caracterizado a América Latina y del constante recurso a los poderes fácticos como medio de solución. Así, por ejemplo, en Ecuador se sucedieron cinco presidentes y una Junta de Salvación Nacional en siete años.

Durante la década de los noventa, la aplicación de las medidas económicas neoliberales y la posterior creación de lo que se denominó segunda generación de reformas del Consenso de Washington conllevaron una serie de transformaciones en el Estado. La intención era crear un nueva matriz más flexible y democrática que, por un lado, diera respuesta a las presiones «desde abajo» y a los procesos de contestación social, pero que, por el otro, fuese compatible con los procesos económicos globales (reformas sectoriales, descentralización o desregularización).

De hecho, la escasez de canales de participación y la exclusión de la cuestión indígena en los procesos de democratización habían provocado la toma de la calle de los sectores populares. En junio de 1990 se convoca en el Ecuador el «Primer Levantamiento Nacional Indígena», que significó un punto de quiebre en la historia reciente del país, ya que «luego del levantamiento, el conjunto del país quedó impactado» (Pajuelo, 2007: 
47). Algo que no será exclusivo del Ecuador y que tendrá una repercusión similar en otros países, como en Bolivia, con «La marcha por el territorio y la dignidad» de los indígenas de tierras bajas en 1990, o el levantamiento zapatista en Chiapas, al sur de México, el 1 de enero de 1994.

Estas marchas, junto al creciente reconocimiento internacional de los pueblos y las nacionalidades indígenas, abrieron un proceso de reformas al respecto, como la ratificación por parte de la gran mayoría de los países latinoamericanos del Convenio 169 de la OIT «Sobre pueblos indígenas y tribales en los países independientes», o la constitucionalización de algunos derechos, como ocurrió con la Constitución ecuatoriana de 1998, donde se reconocía al Ecuador como un Estado «pluricultural y multiétnico» (Artículo $1^{\circ}$ ). Además de la creación de instituciones propias indígenas, como el Consejo de Desarrollo de los Pueblos y Nacionalidades del Ecuador (CODENPE) en 1998 o la Dirección Nacional de Salud Intercultural (DNSPI) en 1999, que se sumaban a otras, como la Dirección Nacional de Educación Bilingüe (DINEIB). Se trata de un periodo de transiciones, lleno de paradojas, con elementos del viejo modelo corporativista, pero también con aspectos novedosos, aunque sin llegar a constituir una nueva matriz. Un Estado poroso tanto al interior como al exterior que permite, en cierto modo, que las identidades locales (indígenas), hasta ese momento subordinadas a la identidad nacional, emerjan en este último terreno y tomen protagonismo, ya sea a través de los procesos descentralizadores (como la Ley de Participación Popular de 1994 en Bolivia) o de la irrupción electoral (como el caso de Pachakutik). Para Yashar (2005), se tratan de respuestas racionales a unas circunstancias institucionales cambiantes, que explican el porqué, el cuándo y el dónde de la visibilización indígena.

LA CONSTITUCIONALIZACIÓN DE LA PLURINACIONALIDAD Y EL POSNEOLIBERALISMO (DÉCADA DE LOS DOS MIL)

En principio, podría parecer que la década de los dos mil supone una especie de «muerte de éxito» para los indígenas. Muchas de sus demandas han sido reconocidas, Naciones Unidas aprobó en 2007 la Declaración sobre los derechos de los pueblos indígenas y se 
ha incluido la plurinacionalidad como forma de Estado en las nuevas Constituciones del Ecuador (2008) y de Bolivia (2009). Junto a ello, puede señalarse el cambio de ciclo en los gobiernos de la región y la irrupción de lo que se ha catalogado como Socialismo del siglo XXI, así como cierta atenuación de las políticas neoliberales, hasta el punto de que se habla ya de un nuevo periodo posneoliberal. Un conjunto de circunstancias sobre las que puede, sobre el papel, dibujarse un entorno favorable para los indígenas.

Sin embargo, esta etapa no significa el fin de los conflictos, sino más bien abre un nuevo periodo, con avances, sin duda, para los pueblos y las nacionalidades indígenas, pero con nuevas cuestiones problemáticas. Entre ellas, la disputa por la plurinacionalidad, un término cuya inclusión resultó costosa en la Constitución ecuatoriana de 2008, por las reticencias de parte del bloque mayoritario en la Asamblea Constituyente, Alianza País, y del propio presidente de la República. Una Asamblea donde la influencia indígena, paradójicamente, fue menor que en la Constituyente celebrada una década antes, hasta el punto de que fue «notorio, a lo largo del proceso, el desinterés del régimen por considerar y debatir en profundidad las demandas de la CONAIE, que fueron presentadas de manera pública en actos masivos con la movilización de miles de indígenas» (Ortiz, 2009: 157).

Esta etapa, que se extiende hasta la actualidad, no representa una ruptura con respecto a las décadas anteriores, ya que hay importantes elementos que se mantienen, como el hiperpresidencialismo, una débil institucionalidad y la ausencia de una nueva matriz estatal (incluso se están recuperando algunos elementos del anterior modelo corporativista), aunque parece que existe cierta transformación del neoliberalismo, al menos en el ámbito retórico, con pronunciamientos en favor de reforzar la soberanía e impulsar políticas sociales focalizadas en los sectores más vulnerables.

Para algunos académicos, como el ecuatoriano Pablo Dávalos (2010), se trata de una nuevo requerimiento del sistema capitalista, que nos sitúa en un momento de «privatización territorial, desposesión y criminalización social», donde los procesos de desarrollo local y de descentralización son funcionales a los macroproyectos regionales, 
de carácter extractivista y productivista, basados en la explotación intensiva de recursos naturales, que son privatizados y de cuyos territorios se expulsan a las poblaciones. Esta perversa dinámica afecta, de manera especial, a pueblos y nacionalidades indígenas, sobre todo a los amazónicos. Planes de desarrollo como el Puebla-Panamá o la Iniciativa de Integración de la Infraestructura Regional en Sur América (IIRSA) son, para el autor, producto de una nueva etapa del sistema-mundo capitalista que recoloca a los países periféricos en su ya clásico rol primario-exportador.

Según el economista, este proceso conduce a la constitución de una «democracia disciplinaria», una suerte de proyecto panóptico «que necesita vigilar, ordenar, sujetar y controlar» (Dávalos, 2010: 364). Y que para poder llevar a buen término su proyecto extractivista se vale de una serie de elementos que disciplinen a la ciudadanía, como políticas de corte asistencialista (que generen fidelidades y un juego de premios y castigos), una retórica de izquierda desarrollista (con pretensiones hegemónicas en la esfera pública, que expulse del debate a todos los disonantes), un marcado discurso nacionalista (que permita estigmatizar a los contrarios) y la utilización de estrategias de biopolítica mediante el uso de tecnócratas (con el fin de influir en los comportamientos y en las subjetividades).

Dentro de esta marco hay que entender algunos de los conflictos ocurridos entre el gobierno del Ecuador y la CONAIE, sobre todo en lo referente a procesos de aprobación de leyes relacionadas con recursos naturales, como la ley de minería, la ley de soberanía alimentaria y la ley de aguas. Una situación que evidencia el choque entre dos proyectos políticos: el gubernamental neodesarrollista, de base extractivista-exportador, y la propuesta de plurinacionalidad indígena, basada en el buen vivir o Sumak Kawsay. Sin entrar ahora en la complejidad de este nuevo escenario, dejamos planteado así el marco para su posterior análisis, en la última parte de este artículo. 


\section{LA CIUDADANÍA ÉTNICA COMO RESPUESTA MULTICULTURALISTA DEL ESTADO NEOLIBERAL}

\section{EL DEBATE LIBERAL SOBRE EL MULTICULTURALISMO}

Los cambios ocurridos en el Estado a partir de las nuevas dinámicas del capitalismo internacional provocaron la apertura de otros debates apenas tenidos en cuenta hasta entonces. Como se ha comentado, la irrupción del neoliberalismo en América Latina y las reformas estatales, de algún modo, supusieron un cambio institucional que favoreció la emergencia de las demandas indígenas, en tanto implicaron una estructura de oportunidad política para los originarios (Yashar, 2005).

Estas reivindicaciones tuvieron como principal respuesta el modelo multicultural de sociedad y la ciudadanía étnica como forma de integración en la comunidad política. Después de veinte años de aplicación del multiculturalismo, puede afirmarse que este significó una vía de reconocimiento cultural de los indígenas, al tiempo que ha supuesto una incapacidad para la materialización de algunas de sus prácticas sociales, económicas y políticas. Como señala Postero, para el caso boliviano «el multiculturalismo neoliberal fue más efectivo como política de reconocimiento que como política de redistribución» (Postero, 2010: 22).

Kymlicka (2003), uno de los principales teóricos del multiculturalismo, plantea pertinentemente algunas de las preguntas clave sobre la pluralidad y presenta una interesante reflexión sobre ciertas limitaciones históricas del Estado y sobre lo complejo de la diversidad en estructuras monoculturales. Aunque más centrado en el caso canadiense, el debate se hace extensible para América Latina, en tanto que la multiculturalidad adquirió un importante peso en el proceso democratizador de los noventa.

Kymlicka cuestiona el carácter neutral del Estado en los asuntos étnicos y, entre otras cosas, se pregunta por qué las minorías nacionales no pueden también participar, con las mismas potestades, en la construcción estatal (Kymlicka, 2003: 45). Sin salirse de los marcos del liberalismo político — al interior de donde abre un debate-, plantea la 
necesidad de tomar en cuenta los derechos colectivos y las políticas de discriminación positiva dentro del Estado. Una propuesta que choca con las posturas liberales más ortodoxas, como la de Sartori (2001) — quien verá en ello un peligro para la libertad individual一, o con postulados que tienen pretensión de neutralidad, como es el caso del patriotismo constitucional de Habemas (1997). De cualquier modo, dentro del debate entre liberales ortodoxos y posturas comunitaristas (vinculadas al relativismo cultural), Kymlicka opta por una fórmula mixta, el culturalismo liberal, como medio de ordenación social de la diversidad.

Como se ha señalado, esta propuesta de Kymlicka no transciende en todo caso el liberalismo. Ello, unido a la aplicación concreta de las políticas multiculturales en América Latina — vinculadas al proyecto neoliberal-, ha provocado una serie de críticas sobre la verdadera naturaleza del multiculturalismo y sobre si, de fondo, se trata de una nueva forma de integración de los indígenas en el capitalismo o si, por el contrario, plantea un proyecto emancipador. Aquí nos posicionaremos en la primera corriente, al entender que las limitaciones de la sociedad multicultural son mayores que las oportunidades para el desarrollo de los derechos indígenas. Tal y como apunta Martínez Novo (2009: 11), «algunos autores comenzaron a señalar que instituciones ligadas al neoliberalismo han fomentado lo identitario y lo cultural en detrimento de reivindicaciones de cambio socio-económico que sean más onerosas al sistema capitalista».

De acuerdo con Díaz Polanco (2005), esta propuesta supone un proceso de «etnofagia», que parte de una reducción culturalista y que implica una simplificación consciente, con un efecto destructor, al devorar «al otro» (en este caso, pueblos y nacionalidades indígenas). Tras ello subyace la lógica de un modelo de integración impulsado por el Estado neoliberal frente a una creciente ola de contestación social. Al tiempo que se exalta la diversidad, se mercantilizan las identidades y se extiende un influjo individualizador que destruye de forma soterrada y continua el tejido comunitario. 
Esta visión olvida el carácter histórico del sujeto indígena, como algo vivo, que ha ocupado una posición subalterna a lo largo de los siglos (Mignolo, 2007), y tiende, por el contrario, a cosificar a las comunidades como entidades ahistóricas. Para Zizek (1998), esto supone un proceso de homogeneización cultural, donde el indígena es entendido como un «otro folclórico», una forma de autocolonización que implica formas de racismo con distancia, ya que tolera a los indígenas como un mal necesario. En términos decoloniales, significa una perpetuación de la colonialidad del ser, del conocer y del poder (Quijano, 2003).

Nuestra hipótesis se sustenta en esta visión, puesto que la ciudadanía étnica supone un reconocimiento, tolerado, de los indígenas, que sin embargo se torna en represión y repudio en el momento en que las comunidades, más allá del encierro culturalista, plantean demandas materiales, ya sean políticas, económicas o sociales.

Ecuador ha sido uno de los países de la región donde mayor penetración ha tenido el influjo del multiculturalismo. Ya sea a través de la creación de instituciones estatales destinadas a la gestión indígena, como el CODENPE, que ha terminado por convertirse en una especie de ONG estatal para los asuntos indígenas, o a través de proyectos de lo que se ha denominado «etnodesarrollo» o desarrollo con identidad. Ejemplo paradigmático de esto último fue el programa PRODEPINE, ${ }^{3}$ impulsado por el Banco Mundial, y que supuso un mecanismo para impulsar las demandas culturales, invisibilizar las socio-económicas y fomentar las lógicas asistencialistas y el proyectismo entre las comunidades (Bretón, 2007: 98).

\section{LA DEMOCRACIA RESTRINGIDA}

En principio, el reconocimiento constitucional de la plurinacionalidad en el Ecuador abre el camino para superar el modelo multicultural, al recoger una demanda histórica de los pueblos y las nacionalidades indígenas y suponer, al menos sobre el papel, un giro en la construcción histórica del Estado. Sin embargo, los tres primeros años de aplicación de estos principios han conducido a un escenario cuanto menos conflictivo, 
caracterizado por una dinámica que explicita una tensión aún irresuelta entre la pervivencia de los principales postulados del multiculturalismo y la introducción de nuevas propuestas de organización social, como la autonomía territorial planteada en las regiones amazónicas, con implicaciones sobre la tradicional concepción unitaria de soberanía.

El hecho de que el punto álgido del conflicto político se sitúe en torno a cuestiones materiales, como los aspectos vinculados al territorio y al alcance de la consulta previa libre e informada de las comunidades indígenas, es un síntoma de la fuerte disputa que se está librando por el control de los recursos naturales. Una pugna que ya no es tanto entre las multinacionales y las comunidades, sino entre estas y el propio Estado, por determinar quién tiene la propiedad del suelo y el subsuelo, y en última instancia por quién tiene la soberanía sobre el territorio.

El resultado de esta lucha definirá, en buena medida, cuál es la aplicación real de la plurinacionalidad más allá del discurso. La creciente criminalización de la protesta que se está dando en el país (con cerca de doscientos dirigentes indígenas detenidos por actos de terrorismo y sabotaje ${ }^{4}$ ) hace pensar en la aplicación del modelo de democracia disciplinaria descrito por Dávalos para el periodo posneoliberal. Una tendencia que perpetúa el patrón de democracia limitada característica de los procesos de transición y democratización latinoamericanos.

En este punto, se propone hacer un breve excursus teórico sobre el origen de estos amarres tan fuertes. Según Lechner (1986, 1996, 1997, 2002), en quien nos basaremos en lo que sigue, tras el fin de las dictaduras en América Latina se constituyó un modelo de democracia restringida, cuya causa se encuentra en el peculiar proceso de transición acontecido durante la década de los ochenta en la región, donde junto a la ola democratizadora se dio de forma paralela otro proceso de modernización.

Si la democratización permitió la instauración de elecciones formales, la modernización se caracterizó por producir una mayor complejidad social, con un incremento en la diferenciación entre los distintos campos de la vida social. Se trata, según Lechner, de 
un proceso de racionalización que impulsa la división de tareas y campos - los procesos sociales-, y que aumenta los niveles de especialización en la organización social, en sistemas funcionales diferenciados. Este proceso incluye además la corriente globalizadora dentro de sí, con lo que la vida social queda subordinada a la racionalidad del mercado.

La irrupción conjunta de estos dos procesos (modernizador/democratizador) en América Latina se ha caracterizado no tanto por su incompatibilidad, sino por un conflicto en la distribución, con un claro predominio de la modernización. Este desequilibrio ha provocado problemas estructurales tanto de anomia social como de falta de confianza en las instituciones estatales, así como una notable incapacidad del Estado para resolver conflictos.

De acuerdo con Lechner, estos rasgos son producto de tres tendencias. La primera se deriva de la desintegración de los vínculos del Estado corporativo, vacío del que emerge una nueva forma de sociabilidad, basada en un «individualismo negativo» que produce a la larga una erosión del «animus societas» — una suerte de cemento social— y que constituye ya no una economía de mercado, sino una sociedad de mercado, donde las normas de este son interiorizadas por todos los miembros de la sociedad. Esto ha provocado la sustitución de la acción colectiva y de los compromisos colectivos por la maximización del beneficio y la exaltación de la individualidad.

La segunda tiene relación con el descentramiento de la política como espacio de coordinación y de conducción de los problemas sociales, de tal manera que la política queda convertida en una entidad autorreferida a sí misma, restringida solo al campo de lo político y ya no al resto de las esferas de la sociedad.

Y la tercera se vincula al carácter de la democracia como forma de legitimación de este modelo a través de la dinámica electoral y no tanto como principio organizador de la sociedad. Para explicar esto, Lechner hace una distinción entre «tener democracia», 
como sistema normativo (algo que, en mayor o menor medida, sí se habría logrado en América Latina), y «gobernar democráticamente», con políticas de tal carácter.

El efecto final de este proceso ha sido la construcción de un modelo donde el Estado y las políticas públicas se han redimensionado, por lo que dejan de estar ya dirigidas a la integración de la sociedad para dedicarse ahora a unos objetivos de competitividad sistémica en un marco de economía internacional. En un sistema en el que se combina la democracia electoral con un arraigado régimen presidencial, donde el presidente -ante la ausencia de mediaciones - asume para sí la capacidad de conducción de la sociedad mediante elementos retóricos de corte nacional-populista y la introducción de mecanismo plebiscitarios. Pero, concluye Lechner, cuya capacidad real de ejercicio político queda limitada por las necesidades de cada momento del mercado mundial, lo que lo convierte, en última instancia, en un tecnócrata del capitalismo.

En este sentido, y para no perdernos en la abstracción, el momento actual del Ecuador refleja parte de las limitaciones propias de una democracia restringida/disciplinaria. Nos encontramos en un escenario protagonizado por un gobierno posneoliberal, el del Rafael Correa, y una nueva Constitución, la de 2008, que introducen cambios notables con respecto a la anterior etapa de neoliberalismo (propia de gobiernos como los de Mahuad o Lucio Gutiérrez y la Constitución de 1998) pero que continúan, de algún modo, sujetos a los mismo cánones del mercado como coordinador social.

En términos generales, puede avanzarse que la propuesta de la plurinacionalidad elaborada por los pueblos y las nacionalidades indígenas plantea una alternativa a este modelo de democracia. El conflicto por los recursos naturales es, quizá, la muestra más evidente de este choque puesto que, al menos en términos teóricos, la constitucionalización del Sumak Kawsay rompe con la lógica del mercado al —en términos de Marx - naturalizar al hombre y humanizar la naturaleza, y reconocer el territorio de las comunidades como espacio de reproducción de la vida social. Ya no se trata, por tanto, solo de defender una visión ancestral o una cosmovisión, sino del reconocimiento de un entorno físico como medio necesario de vida. 
La cuestión abierta ahora es si el Estado plurinacional, una vez que se concrete más allá del planteado en textos y discursos, va a ser capaz de albergar en sus entrañas este modelo alternativo. Un importante reto que supone una contradicción de sí mismo y que, en todo caso, lo convierte en un espacio de disputa entre dos lógicas: la del mercado y la comunitaria.

\section{LAS PROPUESTA PLURINACIONAL Y LAS DIFICULTADES EN SU APLICACIÓN}

\section{LOS PUEBLOS Y NACIONALIDADES INDÍGENAS COMO SUJETOS POLÍTICOS}

En esta última parte se pretende poner el foco de atención en la propuesta de la plurinacionalidad elaborada por los indígenas. La constitucionalización de tal reivindicación supone un importante logro, pero tampoco puede derivarse de ello la garantía de unas nuevas relaciones entre el Estado y la sociedad. El momento actual escenifica una coyuntura crítica: existe un tablero pero en él caben distintos escenarios. La plurinacionalidad aparece así como un concepto abierto, que oscila entre la continuación del anterior modelo multicultural (mediante reformas administrativas de tipo territorial y el reconocimiento de ciertos derechos indígenas, sobre todo en el ámbito lingüístico y cultural) y un cambio sustantivo que suponga un nuevo impulso democratizador, donde el principio democrático se superponga al del mercado, la soberanía territorial se reparta y las instituciones reflejen una mayor diversidad.

Lograda la constitucionalización, se sucede el momento de dotar de prácticas la plurinacionalidad, algo no siempre sencillo y que incluso está provocando fisuras en la propia CONAIE, ya sea por problemas internos, como la lucha de intereses entre «familias» políticas, la compleja relación con Pachakutik o el distanciamiento entre la dirigencia y las bases; ya sea por motivos externos, como la cooptación de líderes, el intento del Estado de intervenir directamente en las comunidades sin la intermediación de la organización, las reformas institucionales planteadas por el gobierno (que afectan, entre otras, a instituciones como el CODENPE o la DINEIB) o las continuas arremetidas del presidente Correa contra los dirigentes indígenas. 
En línea con lo expuesto por Mignolo (2007), los movimientos indígenas encuentran en sus formas de organización y de resistencia un sustrato que les da continuidad histórica, una memoria subalterna que llena de sentido la noción de lo indígena como sujeto político-histórico, más allá de un movimiento social de carácter coyuntural. Existe así una línea entre el pasado y el presente que no ha sido rota ni con la colonia ni con la República que, sin dejar de contener componentes míticos, ha servido como estrategia identitaria de lucha política en la política contemporánea.

Cabe incidir en este uso estratégico de las identidades como elementos construidos, en el sentido dado por Maiz (2007: 396), en el que "las identidades colectivas no se «descubren» ni se «reconocen», sino que se producen políticamente mediante movilización, discurso, regulación institucional y antagonismo en determinados contextos sociales y políticos”, y en la importancia que adquieren los discursos y prácticas de la utopía «como recursos culturales para el cambio político» (Postero, 2007: 4).

Una idea siempre presente en los líderes indígenas, como se muestra en el fragmento de esta entrevista mantenida con Blanca Chancoso, dirigente histórica de la CONAIE:
Algunos logros que hemos tenido han sido gracias a la lucha, algunos compañeros han caído, algunos han muerto, ha habido heridos, han sido esfuerzos. Se ha mantenido esta lucha y siempre intentando que el país tome nuevos rumbos.

Estas palabras ponen de relieve otro aspecto importante: los indígenas han formado y forman parte de la sociedad ecuatoriana. Si bien cuando hablamos de indígenas - $-\mathrm{y}$ más en un país como el Ecuador donde la diversidad es enorme- presuponemos cierta unidad de análisis en el sujeto, lo cual no deja de ser una simplificación debido a las importantes diferencias de pueblos y nacionalidades según las tres grandes áreas geográficas del país (costa, sierra, Amazonía) y al distinto modo de relación que aquéllos han tenido con el Estado. No puede considerarse de igual forma el aislamiento de las comunidades amazónicas con el mestizaje (al menos cultural) propio de los serranos. 
Sin embargo, todos ellos han sufrido una exclusión histórica por parte de la República desde su fundación, una circunstancia que ha provocado que pueblos y nacionalidades indígenas hayan estado menos expuestos al proceso de modernización. En ese sentido, el intento multicultural de fomentar una ciudadanía étnica es una respuesta tardía de incorporar a los indígenas a la comunidad política.

Este distanciamiento es producto de un Estado que históricamente «ha mantenido una relación tensa e irresuelta con los llamados naturales» (Sánchez, 2007: 363) y que ha sido incapaz de dar una respuesta satisfactoria a la cuestión étnica. En cierto modo, la ley de comunas de 1937 y las reformas agrarias de 1964 y de 1973 modificaron la organización socio-económica del país, al romper con el régimen de hacienda, pero no lograron una transformación sustancial en las relaciones políticas de un Estado que se caracterizó por desatender a los indígenas y buscar instancias intermediarias, con lo que se engendraron en su seno distintas «formas ventrílocuas de representación» (Guerrero, 2000) sin mediación directa con los originarios.

Esta tibia relación ha provocado que algunos aspectos básicos del proceso modernizador hayan penetrado con dificultades en las comunidades indígenas. Procedimientos como la democracia electoral, en ocasiones, no han terminado de asentarse del todo al interior del mundo indígena, al ser considerados mecanismos ajenos e, incluso, focos infecciosos que han propagado prácticas de corrupción derivadas de las luchas partidistas. A ello se suma una percepción compartida por parte de algunos dirigentes, para quienes los logros de la organización han sido mayores cuando se han empleado estrategias de movilización antes que el recurso de la estrategia electoral, un debate que subraya el movimiento pendular que ha caracterizado a la CONAIE, entre la políticas de influencia y las políticas de poder (Zamosc, 2007).

Unos recelos que se pueden ver reflejados en las palabras de Gonzalo Guzmán, ex secretario de recursos naturales de la ECUARUNARI, quien en una entrevista afirmaba: 
La participación en la política electoral nos ha hecho daño. Se han ido creando intereses grupales, regionales... Entrar a otro sistema que no ha sido el nuestro. Y a ese sistema que tienes que competirle con las grandes maquinarias electorales. Un sistema que no ha sido nuestro y que si quieres llegar al poder, tienes que usar un sinnúmero de mañas. Y eso tampoco ha sido de las nacionalidades y pueblos (...) Eso ya es sucio, eso ya no es normal (...) Y, claro, nuestra gente ya ha caído en eso.

Aunque con matices, de este distanciamiento pueden sacarse, entre otras, dos conclusiones. La primera destaca el relevante papel de los indígenas ecuatorianos en revitalizar la democracia, al introducir con el levantamiento de 1990 el debate de lo político, hasta el punto de que «la posición de los pueblos indígenas atravesó la ausencia de propuestas de la sociedad»(García, 2003: 209). Un rasgo que lo dota de un especial grado de legitimidad, elemento relacionado con la segunda conclusión: la compleja relación entre la legitimidad y la representatividad.

Una relación contradictoria por la que pueblos y nacionalidades indígenas tienen escasos niveles de representatividad (al menos electoralmente, como por ejemplo ocurrió en la Asamblea Constituyente, donde de un total de 130 asambleístas solo lograron cinco asientos) pero una fuerte legitimidad. Para el actual gobierno de Correa los indígenas representan solo una parte de la sociedad (incluso una parte menor, a juzgar por las palabras del presidente), circunstancia que ha sido empleada como arma arrojadiza contra la CONAIE y que está siendo una fuente inagotable de conflictos entre el gobierno y la organización. Un pulso que se extiende a todos los ámbitos. Por ejemplo, en el campo institucional, el Ejecutivo plantea modificar la actual naturaleza de las instituciones indígenas (que durante años se han considerado entidades con cierto margen de autonomía con respecto a las estructuras ministeriales) para transformarlas en una política sectorial más (de forma que, por ejemplo, el CODENPE quedaría integrado en los Consejos Nacionales de Igualdad). 


\section{UN CONTENIDO SUJETO A DEBATE}

A diferencia de otras corrientes indígenas de la región, una de las peculiaridades más marcadas de los indios ecuatorianos desde el levantamiento de 1990 ha sido su propuesta inclusiva, para toda la sociedad. Como explica Becker (2008: 170), «la CONAIE rechazó la posición racista de posicionar a los indígenas en lucha con los mestizos (...) Optó por una tercera vía en la cual la lucha adquiere una doble dimensión de organización clasista junto a otros movimientos populares con la intención de transformar la sociedad, y de organización étnica independiente en defensa de las culturas indígenas». De las palabras de Luis Macas, ex presidente de la CONAIE, puede traslucirse esa visión:

No es un tema de reivindicación de los pueblos indígenas. Y yo diría algo más (...) no tiene siquiera que ver con el reconocimiento de la diversidad identitaria de este país. Yo lo planteo como algo mucho más radical. Esto es un proyecto popular de transformación de este Estado. Es la transformación política, económica y social de este país. Entonces, no es un planteamiento particular aislado de los pueblos indígenas para su reconocimiento. Es un proyecto político y social. Es un proyecto popular, en definitiva, que va en dirección de la transformación profunda

La propuesta plurinacional de los pueblos y las nacionalidades indígenas adquiere, de esta forma, las dimensiones de gran relato, al aspirar a una transformación radical de las relaciones entre Estado y la sociedad. Aquí surge la pregunta sobre hacia dónde deberían, a juicio de los indígenas, caminar esas relaciones. Según argumenta el también ex presidente de la CONAIE Marlon Santi, el cambio comienza por el reconocimiento comunitario como modo de organización en el interior del Estado:

La CONAIE plantea un modelo muy distinto, que no es socialista ni comunista, es comunitario. Nada para los indios, todo para todos. Es a lo que le tienen miedo, cuando decimos todos, nada para los indios, todo para todos significa que no queremos que en el Ecuador exista poder económico que domine. Ése es el miedo, las leyes para todos no solo para el privilegio. Instituciones para todos, no solo para 
el poder económico. Tierra para todos, no solo para terratenientes. Agua para todos. Entonces, claro, estamos rompiendo la lógica de capitalismo que se ha hecho. El pensamiento indígena es colectivo.

En términos generales, la propuesta indígena puede interpretarse como un metarrelato, una concepción tal vez utópica de la sociedad que plantea un modelo alternativo a la democracia existente. El proyecto político elaborado por la CONAIE de 2007 ante la convocatoria de la Asamblea Constituyente ${ }^{5}$ recogía esta visión en la que la plurinacionalidad se entiende como: «un sistema de gobierno y un modelo de organización política, económica y sociocultural, que propugna la justicia, las libertades individuales y colectivas, el respeto, la reciprocidad, la solidaridad, el desarrollo equitativo del conjunto de la sociedad ecuatoriana y de todas sus regiones y culturas, en base al reconocimiento jurídico-político y cultural de todas las nacionalidades y pueblos que conforman el Ecuador» (CONAIE, 2007: 17).

Una vez más la referencia es al conjunto de la sociedad ecuatoriana, y la apelación a las distintas nacionalidades, ${ }^{6}$ lejos de plantearse como un intento secesionista, se presenta como un tipo de construcción nacional «desde abajo», compuesta por los históricamente subalternos, que pretende dialogar —interculturalmente ${ }^{7}$ - con la nación construida «desde arriba», de raíz liberal, fundada con la República. A este respecto, Almeida diferencia entre nación y nacionalidad, ya que «mientras la nación es un fenómeno de la época del capitalismo, la nacionalidad se consolida en la nación (...) Se ha optado por la categoría nacionalidad porque expresa la reivindicación política a partir de la conciencia histórica» (2008: 43). Una concepción, esta última, que hace referencia «a un concepto comunitario no liberal de nación (...) que conlleva un concepto de autodeterminación, pero no de independencia» (De Sousa Santos, 2007: 31).

El intento por definir estos conceptos son muestra de que, lejos de cerrado, el debate está abierto, y de que el resultado final de este juego de equilibrios entre Estado, nación y nacionalidades marcará la construcción del «nosotros común» en el país. Kymlicka, 
refiriéndose a las demandas de las minorías nacionales, plantea la complejidad que supone este tipo de articulación, «que no consiste simplemente en que la comunidad política sea culturalmente diversa (...) [sino que] consiste en que exista más de una comunidad política» (Kymlicka, 2003: 160). Una cuestión a la que la plurinacionalidad, posiblemente, también tendrá que dar respuesta.

Es justo en este punto, sobre cómo concretar lo plurinacional en prácticas, sobre qué procesos deben darse y sobre qué aspectos son objeto de cambio, donde los conflictos florecen con mayor intensidad, y no siempre con consenso siquiera al interior de las propias comunidades indígenas. De acuerdo con Alberto Acosta, ex presidente de la Asamblea Constituyente y persona cercana a la CONAIE, hay un reconocimiento generalizado del carácter plurinacional pero también hay momentos de confusión, sobre todo cuando se trata de plantear propuestas concretas:

La plurinacionalidad es un mensaje fuerte pero al que todavía no se le ha dado el contenido adecuado. En eso tienen culpa, en primer lugar, los propios indígenas. Ése es mi criterio personal. Porque no han aterrizado sus propuestas mucho más de lo que deberían hacer (...) Viene una etapa de cristalización muy difícil, de disputa del sentido histórico. Mi criterio es que el movimiento indígena no ha asumido eso con absoluta claridad. Están más preocupados en los puntos en los que chocan con Correa que en los puntos en los que ellos pueden liderar el proceso.

A modo de síntesis, se presenta en último lugar un mapa conceptual que pretende recopilar la visión indígena sobre lo que implica —o debe implicar- el Estado plurinacional. Este esquema se ha elaborado a partir de la realización de diez entrevistas a otros tantos líderes indígenas del Ecuador, ${ }^{8}$ con la pregunta principal: ¿qué entiende usted por la plurinacionalidad? De las respuestas, hemos seleccionado los principales términos que los dirigentes asocian a la construcción del Estado plurinacional, como puede verse en la siguiente figura. 
Figura 1: La plurinacionalidad y los términos que la dirigencia indígena le asocia

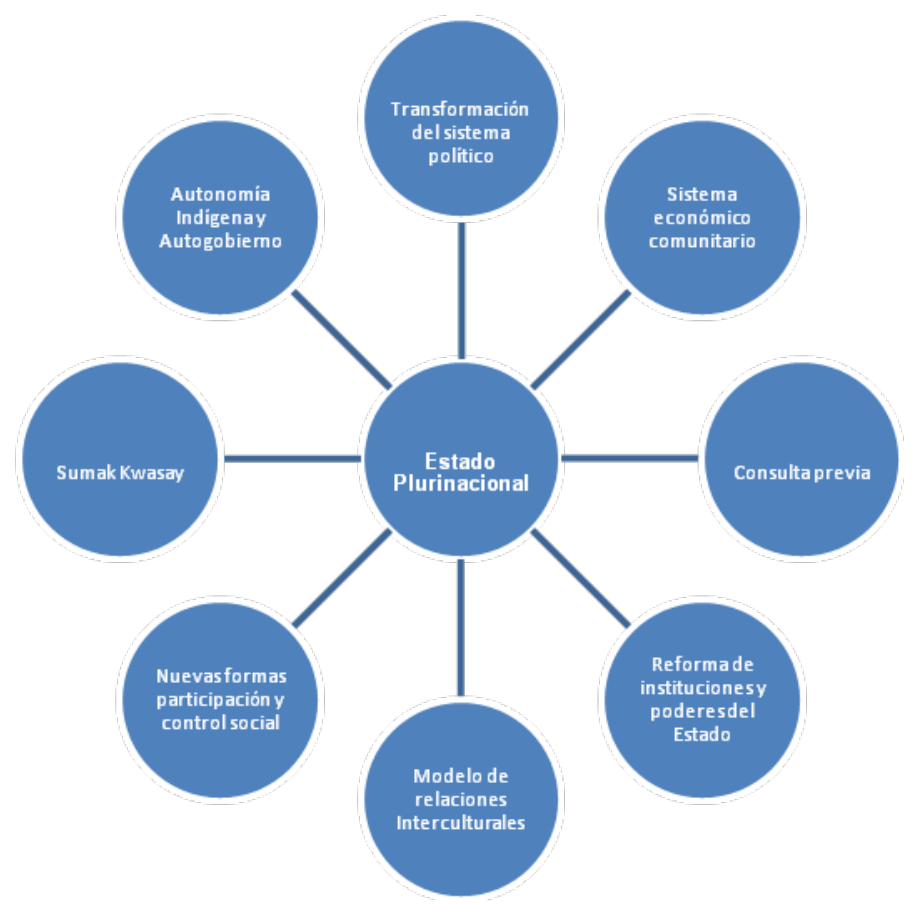

Fuente: Elaboración propia.

\section{CONCLUSIÓN: UN MOMENTO DE BIFURCACIÓN}

Al principio del texto se preguntaba qué más piden los indígenas. Como ha pretendido exponerse a lo largo del artículo, lo que parece claro es que, en todo caso, están pidiendo algo más, al menos algo más que un mero reconocimiento cultural en la Constitución. Respuestas basadas en procesos de lo que Diaz Polanco (2005) caracteriza como etnofagia, en las que la plurinacionalidad termine por concretarse en la difusión de la imagen del Ecuador como un país lleno de folclore y de diversidad cultural, puede incluso llegar a provocar un resultado contraproducente, al estigmatizar aquellas propuestas indígenas más críticas que reclamen procesos de transformación social. Los casos de criminalización de la protesta, la militarización del territorio y las arremetidas verbales del presidente de la República contra dirigentes indígenas en las cadenas sabatinas hacen pensar en que este camino ya ha 
comenzado. Habrá que esperar a ver cómo evoluciona el sentimiento racista en la opinión pública.

Como se ha argumentado, la propuesta de la plurinacionalidad que parte de los pueblos y las nacionalidades demanda un cambio radical de la sociedad y del Estado. A pesar de las contradicciones que puedan detectarse en los discursos indígenas y de las ambigüedades que, en ocasiones, caracterizan a sus propuestas, puede afirmarse que, en términos generales, su planteamiento pone en tela de juicio el actual modelo de organización, y evidencia la carencia de un cemento social sólido (reflejado en la incapacidad institucional). Aspectos elementales como el concepto de soberanía quedan ahora en entredicho frente al reto que suponen nuevas realidades como la autonomía territorial o los procesos interculturales, con lo que el principio de unicidad del poder del Estado-nación comienza a erosionarse.

Es precisamente la disputa por los recursos naturales el tema que visibiliza probablemente como ningún otro el nivel de violencia al que puede llegar el choque entre el Estado y las poblaciones. La contestación social iniciada por los indígenas —no solo en el Ecuador sino en toda América Latina- en defensa de sus territorios ha puesto de manifiesto el carácter disciplinario de las actuales democracias. Nos encontramos en una coyuntura histórica de encrucijada, donde los grandes proyectos de exploración, explotación y exportación de recursos naturales impulsados por los gobiernos y ejecutados por las multinacionales pueden, a mediano plazo, hacer peligrar el hábitat de muchas comunidades indígenas de la región.

Hasta dónde llegue el alcance de la autonomía territorial y en qué términos se aplique la consulta previa, libre e informada determinará en parte el verdadero significado de la plurinacionalidad, más allá de las elucubraciones académicas y de los círculos de intelectuales impulsados por los gobiernos. 


\section{BIBLIOGRAFÍA}

Almeida, Ileana, 2008, El Estado Plurinacional. Valor histórico y libertad política para los indígenas ecuatorianos, Abya-Yala Quito.

Becker, Marc, 2008, Indians and leftist in the making of Ecuador's modern indigenous movements, Duke University Press, Durham.

Bengoa, José, 2000, La emergencia indígena en América Latina, Fondo de Cultura Económica, Santiago de Chile.

Bretón, Víctor, 2007, «A vueltas con el neo-indigenismo etnófago: la experiencia Prodepine o los límites del multiculturalismo neoliberal», en Íconos Revista de Ciencias Sociales, No 29, Flacso Ecuador, pp. 95-104.

Cavarozzi, Marcelo, 1991, «Más allá de las transiciones a la democracia en América Latina», en Revista de Estudios Políticos, núm. 74, octubre-diciembre, pp. 85-111.

CONAIE, 2007, Proyecto político de las nacionalidades del Ecuador, CONAIE, Quito

Dávalos, Pablo, 2005, «Movimiento indígena ecuatoriano: construcción política y epistémica», en Cultura, política y sociedad. Perspectivas latinoamericanas, compilado por D. Mato,, CLACSO, Buenos Aires, pp. 337-357.

Dávalos, Pablo, 2010, La democracia disciplinaria. El proyecto posneoliberal para América Latina, CODEU, Quito.

De Sousa Santos, Boaventura, 2007, «La reinvención del Estado y el Estado plurinacional», en OSAL: Observatorio Social de América Latina, núm. 22, septiembre 2007, CLACSO, Buenos Aires, pp. 25-46. 
Díaz Polanco, Héctor, 2005, Etnofagia y multiculturalismo (on-line), disponible en http://www.estudiosecologistas.org/docs/reflexion/indigenas/etnofagia.pdf.

García, Fernando, 2003, «Política, Estado y diversidad cultural: a propósito del movimiento indígena ecuatoriano», Estado, etnicidad y movimientos sociales en América Latina: Ecuador en crisis, editado por V. Bretón, y F. García, Icaria, Barcelona, pp. 193-215.

Garretón, Manuel Antonio, 1997, «Revisando las transiciones democráticas en América Latina», en Nueva Sociedad, núm. 148, marzo-abril 1997, pp. 20-29.

Guerrero, Andrés, 2000, «El proceso de identificación: sentido común ciudadano, ventriloquía y transescritura», en Etnicidades Antología Ciencias Sociales Introducción, compilado por A. Guerrero, FLACSO Ecuador, Quito, pp. 9-60.

Habermas, Jürgen, 1992, «Citizenship and national identity: some reflections on the future of Europe», en Praxis Internationa, vol. 12, núm. 1, 1992, pp. 1-19.

Hale, Charles R., 2002, «Does multiculturalism menace? Governance, cultural rights and the politics of identity in Guatemala», en Journal of Latin America Studies, vol. 34, núm. 3, Cambridge University Press, pp. 485-524.

Kymlicka, Will, 2003, La política vernácula. Nacionalismo, multiculturalismo y ciudadanía, Paidós, Barcelona.

Lechner, Norbert, 1986, La conflictiva y nunca acabada construcción del orden deseado, Centro de Investigaciones Sociológicas (CIS), Madrid.

Lechner, Norbert, 1996, «La política ya no es lo que fue», en Nueva Sociedad, núm. 144, julio-agosto 1996, pp. 63-74. 
Lechner, Norbert, 1997, «Tres formas de coordinación social» en Revista de la CEPAL, núm. 61, abril, pp. 7-17.

Lechner, Norbert, 2002, Las sombras del mañana. La dimensión subjetiva de la política, LOM Ediciones, Santiago.

Maiz, Ramón, 2007, «México: la guerra de las palabras, marcos interpretativos y estrategias de identitarias en el discurso político del EZLN (1994-2007)», en Pueblos indígenas y política en América Latina, Fundación CIDOB, Barcelona pp. 393-434.

Martínez Novo, Carmen, 2009, «Introducción», en Martínez Novo, C. (comp.), Repensando los movimientos indígenas, Quito, Flacso Ecuador, pp. 9-36.

Mignolo, Walter D., 2007, La idea de América Latina. La herida colonial y la opción decolonial, Gedisa, Barcelona.

O’Donnell, Guillermo, 1994, «Delegative Democracy», en Journal of Democracy, vol. 5, núm. 1. January, pp. 55-69.

Ortiz, Pablo, 2009, «Ecuador», en El mundo indígena 2009, Lima, IWGIA.

Pajuelo, Ramón, 2007, Reinventando comunidades imaginadas. Movimientos indígenas, nación y procesos sociopolíticos en los países centroandinos, Instituto de Estudios Peruanos, Lima.

Postero, Nancy, 2007, «Andean Utopias in Evo Morales’s Bolivia», en Latin American and Caribbean Ethnic Studies, vol. 2, núm. 1, pp. 1-28.

Postero, Nancy, 2010, «Morale's MAS Government. Building indigenous popular hegemony in Bolivia», en Latin American Perspectives, vol. 37, núm. 3, pp. 18-34. 
Quijano, Aníbal, 2003, La colonialidad del poder, eurocentrismo y América Latina, Cholonautas, disponible en: http://www.cholonautas.edu.pe/modulo/upload/Anibal\%20Quijano.pdf

Sánchez, Francisco, 2007, «Ecuador: el indio como problema», en Pueblos indígenas y política en América Latina, Barcelona, Fundación CIDOB, pp. 361-362.

Sartori, Giovanni, 2001, La sociedad multiétnica: pluralismo, multiculturalismo y extranjeros, Taurus, México, D.F.

Segato, Rita Laura, 2007, La nación y sus otros. Raza, etnicidad y diversidad religiosa en tiempos de política de identidad, Prometeo, Buenos Aires.

Simbaña, Floresmilo, 2008, «La plurinacionalidad en la nueva Constitución», en Muñoz, F. (comp.), La Asamblea Constituyente: contexto, funcionamiento y estrategia de actores, Quito: La Tendencia (on-line), disponible en http://www.institutgouvernance.org/fr/analyse/fiche-analyse-453.html

Walsh, Catherine, 2009, Interculturalidad, Estado, Sociedad. Luchas (de)coloniales de nuestra época, Universidad Andina Simón Bolívar-Abya-Yala, Quito.

Yashar, Deborah, 2005, Contesting Citizenship in Latin American. The Rise of Indigenous Movements and the Postliberal Challenge, Cambridge University Press, Nueva York.

Zamosc, León, 2007, «The Indian Movement and Political Democracy in Ecuador», en Latin American Politics and Society, vol. 49, núm. 3, University of Miami, pp. 1-34.

Zizek, Slavoj, 1998, «Multiculturalismo o la lógica cultural del capitalismo multinacional», en Jamenson, Fredic y Zizek (comp.), Estudios culturales. Reflexiones sobre el multiculturalismo, Paidós, Buenos Aires, pp. 137-188. 


\title{
NOTAS
}

\begin{abstract}
${ }^{1} \mathrm{Al}$ respecto, Correa aseguró que «la propuesta de plurinacionalidad que tiene el Gobierno es la más sensata y realista», insistiendo en que «la otra, solo representa a un 2 \%» (Simbaña, 2008). En un discurso pronunciado ante la Asamblea Constituyente el 26 de julio de 2008, Correa advertía que «el mayor peligro para nuestro proyecto de país es el izquierdismo y el ecologismo infantil. Temo que no me equivoque, aunque tal vez me faltó añadir el indigenismo infantil».

${ }^{2}$ Estas entrevistas fueron realizadas por el autor en marzo de 2010, con financiación de la Fundación Carolina, en el marco del proyecto de investigación «La influencia indígena en la transformación estatal: interculturalidad y etnodesarrollo en los procesos constituyentes de Ecuador y Bolivia», dirigido por la doctora María Esther del Campo.

${ }^{3}$ Proyecto de Desarrollo de los Pueblos Indígenas y Negros del Ecuador, aprobado en 1998, cuyos fondos provenían de un préstamo del Banco Mundial (BM) y de la Organización para la Agricultura y la Alimentación (FAO). Inspirado en la filosofía del «etnodesarrollo», el programa - planeado para cuatro años y con unos fondos de 50 millones de dólares- preveía subsidios directos. En 2005, la CONAIE manifestó su rechazo a la segunda parte del desarrollo de este proyecto, al considerarlo perjudicial para el fortalecimiento de los pueblos y nacionalidades indígenas.

${ }^{4}$ Véase: http://www.eluniverso.com/2011/02/13/1/1355/protesta-social-ve-cercada-acusaciones-sabotajeterrorismo.html

${ }^{5}$ CONAIE (2007): Proyecto político de las nacionalidades del Ecuador. Quito: CONAIE.

${ }^{6}$ Se considera que en el Ecuador existen 14 nacionalidades (Shuar, Achuar, Huaorani, Cofán, Siona, Secoya, Shiwiar, Andoas, Zápara, Tsáchila, Chachi, Awá, Épera y Kichwa) y 19 pueblos (Pasto, Paltas, Tomabela, Saraguro, Kañari, Puruwá, Panzaleo, Chibuleo, Kizapincha, Salasaca, Kitu-Kara, Cayambi, Karanki, Natabuela, Otavalo, Manta, Puná, Huankavilka y Kichwas).

${ }^{7}$ Entendida la interculturalidad como «concepto y práctica, proceso y proyecto, la interculturalidad significa el contacto e intercambio entre culturas en términos equitativos, en condiciones de igualdad (...) es un proceso y una actividad continua; la interculturalidad debiera ser pensada menos como sustantivo y más como verbo de acción, tarea de toda la sociedad» (Walsh, 2009: 41)

${ }^{8}$ Los diez dirigentes son: Luis Macas, Marlon Santi, Blanco Chancoso y Humberto Cholango (CONAIE); Delfin Tenesaca y Gonzalo Guzmán (ECUARUNARI); Raúl Tapuyo (CONAICE); Jorge Guamán, Gerónimo Yantalema y Gilberto Guamangate (Pachakutick).
\end{abstract}

Fecha de recepción: 24 de junio de 2011.

Fecha de aceptación: 25 de enero de 2012. 